\title{
Formulation of a Topical Sun Protection Cream for People with Albinism
}

\section{M.L. MOLOISANE ${ }^{1}$, W. LIEBENBERG ${ }^{2}$, A.P. LÖTTER ${ }^{2}$ AND M. DE VILLIERS ${ }^{3}$ *}

\author{
'Medicines Control Council, Private Bag X828, Pretoria 0001, South Africa. \\ ${ }^{2}$ Research Institute for Industrial Pharmacy, Potchefstroom University for Christian Higher Education, \\ Potchefstroom 2520, South Africa. \\ ${ }^{3}$ Pharmaceutical Sciences Division, School of Pharmacy, University of Wisconsin, Madison, WI 53705. \\ USA
}

The aim of this investigation was to design and develop a sun protection product for people with albinism that is affordable, applicable to their specific skin condition, and provide them with the maximum sun protection possible. To achieve the required Sun Protection Factor value of $>20$, simple creams were combined with very fine inorganic oxides (zinc oxide and titanium dioxide) and organic sunscreen filters (2-ethylhexyl cinnamate and octyl methoxycinnamate). These combinations also ensured high $U V_{A} / U V_{B}$ protection ratios. The physical stability and change in Sun Protection Factor for products stored for 8 weeks at $25^{\circ} \mathrm{C}(60 \% \mathrm{RH})$ and 45 ${ }^{\circ} \mathrm{C}(75 \% \mathrm{RH})$ were also determined. Hypoallergenic and physically stable product(s) were formulated with SPF values between 20 to 30 and $U V_{A} / U V_{B}$ ratios above 0.8 by combining simple cream formulations with fine particle inorganic oxides and organic UV protection agents. This approach offered an opportunity to formulate broad-spectrum sunscreen products that met the needs of albinos.

Key words: Sun protection cream, Sun protection factor, albinism

\section{INTRODUCTION}

The word "albinism" refers to a group of inherited conditions, which might be congenital, generalized, and hypomelanotic, in which melanocytes are present in the integument and specific ocular signs accompany the eyes [1]. Dermatologists have recognized that the more melanin one has in the skin the less sun damage such as wrinkling, incidence of actinic keratoses, basal and squamous cell carcinomas, and melanoma occurs [2]. People with albinism have no natural UV protection, therefore, their skin is more sensitive to sunlight and they develop sunburn. They therefore need maximum protection to prevent burning and to reduce skin cancer.

Under the tropical African sun, the melanindeficient skin of albinos develops wrinkles, lentigines, actinic keratoses (small reddish or tan thickenings with an irregular rough or scaly surface which develop on the face and the backs of hands, especially on bald scalps) and epitheliomata from which they may die in early adult life or in middle age [3]. The question is therefore, "which sunscreen should people with albinism use?" One rule is that people with albinism should use sunscreens labeled with a Sun Protection Factor (SPF) of 20 to 30 . This number comes from a standard laboratory test that measures the time it takes people wearing a standard amount of sunscreen to sunburn under a standard ultraviolet lamp, compared to the time with no sunscreen [4].

The present study was undertaken to design a sunscreen product that would meet the needs of albinos. These needs include a SPF factor $>20$, acceptable color, adequate skin moisturizing and affordability.

\section{MATERIALS AND METHODS}

\section{Materials}

Mineral oil, cetyl alcohol, glycerol monostearate (GMS), methyl paraben, and propyl paraben were BP grade materials and were obtained from Saarchem (Krugersdorp, South Africa). Deionized water fit for chromatography were used. Parsol MCX (2-ethylhexyl cinnamate, Roche, Basel, 
Switzerland) and Neo Heliopan (octyl methoxycinnamate, Haarmann and Reimer, Holzminden, Germany) are organic UVA filters that are globally approved. Spectraveil MOTG (mixture of zinc oxide (60\%), caprylic/capric triglyceride, mineral oil, and polyhydroxystearic acid) and Tioveil AQ-N (mixture of titanium dioxide $(40 \%)$, alumina, silica and sodium polyacrylate) are inorganic physical sun blocking agents obtained from Uniqema (Bryanston, South Africa).

\section{In-vitro determination of sun protection factors} (SPF)

An instrumental sun protection factor (SPF) analyzer (SPF-290 Analyzer, Optometrics, Ayer, $M A$, USA) was used for the rapid and accurate invitro determinations of the SPF of the sunscreen lotions and creams. This SPF analyzer is a microcomputer-controlled UV-VIS scanning spectrophotometer. Covering both the $U_{B}$ and $U V_{A}$ spectral regions, the system automatically scans over the 290 to $400 \mathrm{~nm}$ wavelength range, accumulating and storing data at $5 \mathrm{~nm}$ intervals (Figure 1).

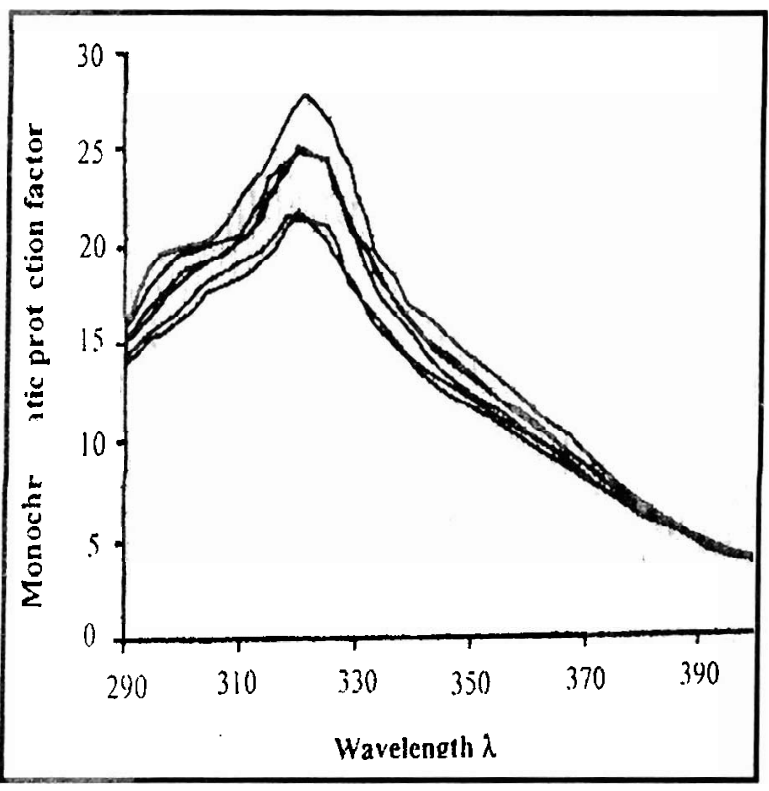

Figure 1: A series of monochromatic protection factor (MPF) values as a function of wavelength

A monochromatic protection factor (MPF) is calculated and plotted for each run, using data collected at 23 specific wavelengths. To compensate for variations in sample application and for wavelength-dependent variables of the substrate, 12 separate areas of a sample can be analysed. Surgical tape was used as the medium to which the samples were applied. The runs are averaged, and by using solar irradiance and erythemal constants, the SPF and other factors are calculated from the MPF's as described by Diffey and Robson [5],

$$
S P F=\frac{\sum_{290}^{400} E_{\lambda} B_{\lambda}}{\sum_{290}^{400} \frac{E_{\lambda} B_{\lambda}}{M P F_{\lambda}}}
$$

where: $E_{\lambda}$ is the spectral irradiance of terrestrial sunlight under (midday midsummer sunlight at $40^{\circ} \mathrm{N}$ solar zenith angle $20^{\circ}$ ) and $\mathrm{B}_{\lambda}$ is the erythemal effectiveness i.e. the relative effectiveness of UV radiation at a specific wavelength in producing a delayed erythema in human skin (i.e. CIE "Reference Action Spectrum). The mean absorbance ratio $\left(U_{A} / U V_{B}\right)$ was also calculated as follows,

$U V_{A} / U V_{B}$ ratio $=\frac{U V_{A}}{U V_{B}}$ Area per unit $\lambda$

\section{Formulation}

Preliminary preparation of various creams and lotions lead to the production of 10 prototype formulations that were subjected to SPF analysis. Three of the formulations had initial SPF values above 20. The compositions of these formulations are listed in Table 1. The formulae in Table 1 were manufactured using the following method. First, the ingredients of Phase A were weighed and heated to $75{ }^{\circ} \mathrm{C}$, mixed until a uniform mixture was obtained. Then, in a separate vessel, the ingredients of Phase $\mathrm{B}$ were also weighed and heated to between $75{ }^{\circ} \mathrm{C}-80{ }^{\circ} \mathrm{C}$ until a uniform mixture was obtained. When both phases were at the proper temperature, Phase $B$ was added to Phase A with constant agitation, the mixture was mixed for ten minutes at $75^{\circ} \mathrm{C}-80^{\circ} \mathrm{C}$, and then cooled slowly to $25^{\circ} \mathrm{C}$ with proper agitation.

\section{Stability testing}

The three prototype creams were subjected to four two-week cycles. One set of samples were kept 
for 1 week at $4{ }^{\circ} \mathrm{C}$ in a refrigerator and then one week at $25{ }^{\circ} \mathrm{C}$ (60\% relative humidity). Another set of samples were kept for 1 week at $4{ }^{\circ} \mathrm{C}$ and another week at $40{ }^{\circ} \mathrm{C}$ ( $75 \%$ relative humidity) (total of 8 weeks). The following parameters were measured after every 2-week cycle: $\mathrm{pH}$ (pH 300, Carl Zeiss, Esslingen, Germany); viscosity (Cone plate viscometer, Brookefield HBT, Brookfield, Middleboro, MA, USA); density (Model DMA 38, Anton Paar, Graz, Austria); spreadibility (method reported by Narsai et al. [6]); visual appearance; SPF value.

\section{RESULTS}

Initially 10 prototype formulations were prepared and the SPF factors measured. For most of the products the in-vitro SPF factors ranged from 614 and these formulations were not considered ideal for albinos. Three formulations had SPF factors ranging from 20-33. The compositions of these formulations are given in Table 1 and SPF factors and $U V_{A} / U V_{B}$ ratios are listed in Table 2. Laboratory scale batches of the formulations listed in Table 1 were prepared and subjected to the stability program.

Table 1: The three prototype sunscreen formulae that were subjected to stability testing

\begin{tabular}{lccc}
\hline Ingredients & $\begin{array}{c}\text { Form- } \\
\text { ula 1 }\end{array}$ & $\begin{array}{c}\text { Form- } \\
\text { ula 2 }\end{array}$ & $\begin{array}{c}\text { Form- } \\
\text { ula 3 }\end{array}$ \\
\hline Phase A & $\%$ & $\%$ & $\%$ \\
\hline Mineral oil & 15.00 & 15.00 & 15.00 \\
Cetyl alcohol & 2.50 & 2.50 & 2.50 \\
$\begin{array}{l}\text { Glycerol } \\
\text { monostearate }\end{array}$ & 7.50 & 7.50 & 7.50 \\
Parsol MCX & 5.25 & 3.00 & \\
$\begin{array}{l}\text { Neo Heliopan } \\
\text { Spectraveil }\end{array}$ & - & - & 5.04 \\
MOTG & 30.00 & & 25.00 \\
\hline Phase B & $\%$ & $\%$ & $\%$ \\
\hline $\begin{array}{l}\text { Methyl } \\
\text { paraben }\end{array}$ & 0.20 & 0.20 & 0.20 \\
Propyl paraben & 0.04 & 0.04 & 0.04 \\
$\begin{array}{l}\text { Tioveil AQ-N } \\
\text { Deionised }\end{array}$ & - & 30.00 & 20.00 \\
water & q.s. & q.s. & q.s. \\
\hline
\end{tabular}

Table 2: Sun protection factor and $U V_{A} / U V_{B}$ ratios of the prototype formulations before and after stability testing

\begin{tabular}{|c|c|c|c|}
\hline & $\begin{array}{l}\text { Formu- } \\
\text { lation } 1 \\
\end{array}$ & $\begin{array}{l}\text { Formu- } \\
\text { lation } 2 \\
\end{array}$ & $\begin{array}{l}\text { Formu- } \\
\text { lation } 3 \\
\end{array}$ \\
\hline \multicolumn{4}{|l|}{0 weeks } \\
\hline SPF & $20 \pm 1.5$ & $30 \pm 2.6$ & $30 \pm 2.7$ \\
\hline $\mathrm{UV}_{\mathrm{A}} / \mathrm{UV}_{\mathrm{B}}$ & 0.8 & 0.9 & 0.8 \\
\hline \multicolumn{4}{|c|}{8 weeks at $25^{\circ} \mathrm{C}$} \\
\hline SPF & $21 \pm 1.3$ & $29 \pm 2.1$ & $31 \pm 2.0$ \\
\hline $\mathrm{UV}_{\mathrm{A}} / \mathrm{UV}_{\mathrm{B}}$ & 0.8 & 0.9 & 0.8 \\
\hline \multicolumn{4}{|c|}{8 weeks at $40^{\circ} \mathrm{C}$} \\
\hline SPF & $19 \pm 2.3$ & $41 \pm 2.4$ & $40 \pm 2.2$ \\
\hline$U_{\mathrm{A}} / \mathrm{UV}_{\mathrm{B}}$ & 0.8 & 0.8 & 1.0 \\
\hline
\end{tabular}

SPF: sun protection value. $U_{A}$ : ultraviolet $A . \quad U_{B}$ : ultraviolet $\mathrm{B}$

After each two-week cycle several properties of the creams were measured. The pH's of the creams were 8.3 for Formulation 1, 9.0 for Formulation 2 and 8.2 for Formulation 3 and no statistically significant changes in the $\mathrm{pH}$ of the creams were observed during stability testing. The apparent densities of the creams were the same (mean $1.21 \pm 0.23 \mathrm{~g} / \mathrm{cm}^{3}$ ) and during stability testing the density of the creams remained constant.

Viscosity measurements $\left(\mathrm{N} \cdot \mathrm{s} / \mathrm{m}^{2}\right)$ indicated that during storage there was a slight increase in the viscosity of the creams. The three creams initially had the same viscosity $\pm 20 \mathrm{~N} \cdot \mathrm{s} / \mathrm{m}^{2}$, but the viscosity of Formulation 1 increased to $40 \mathrm{~N} \cdot \mathrm{s} / \mathrm{m}^{2}$, Formulation 2 to $28 \mathrm{~N} \cdot \mathrm{s} / \mathrm{m}^{2}$, and Formulation 3 to $60 \mathrm{~N} \cdot \mathrm{s} / \mathrm{m}^{2}$. The increase in viscosity was more pronounced at $40^{\circ} \mathrm{C}$ compared to $25^{\circ} \mathrm{C}$ as shown in Figure 2. This increase in the viscosity of the creams meant that the spreadibility of the creams decreased with time as shown in Figure 3. To visually assess the creams the general appearance were compared after each cycle to look for any dramatic changes. At the beginning of the assessment of the creams, Formulations 1 and 2 were off-white and shiny, and Formulation 3 was white and shiny. The texture of both 1 and 2 was smooth and soft while that of 3 was rougher and harder. By the end of the third cycle, Formulation 3 had become very dry while there was no appreciable change in the appearance or texture of 
the other two creams. The texture and appearance of these creams remained the same for the remainder of the study and compared well with each other even at different storage temperatures.

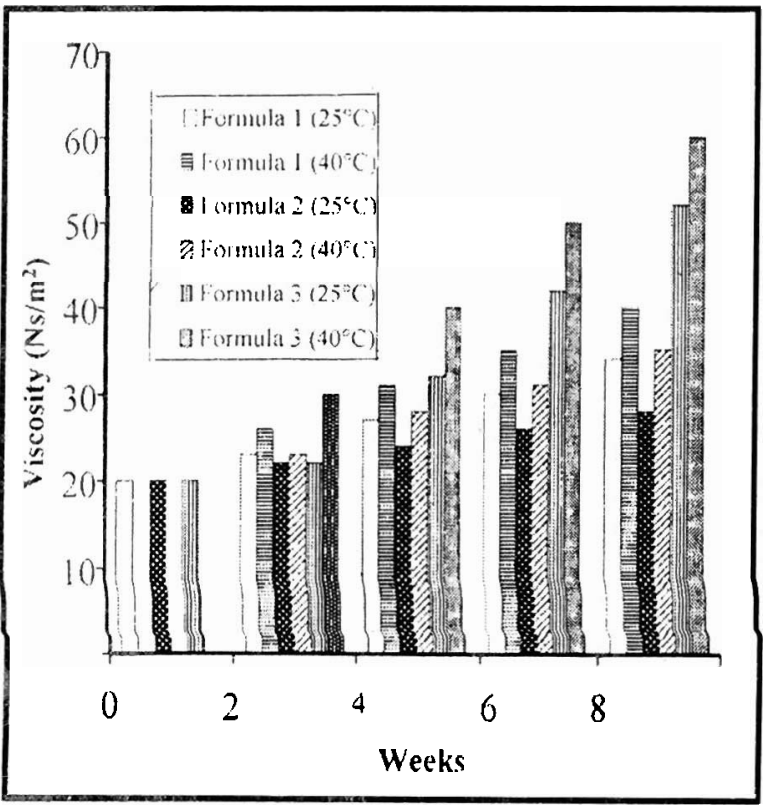

Figure 2: The change in viscosity of the three prototype formulations

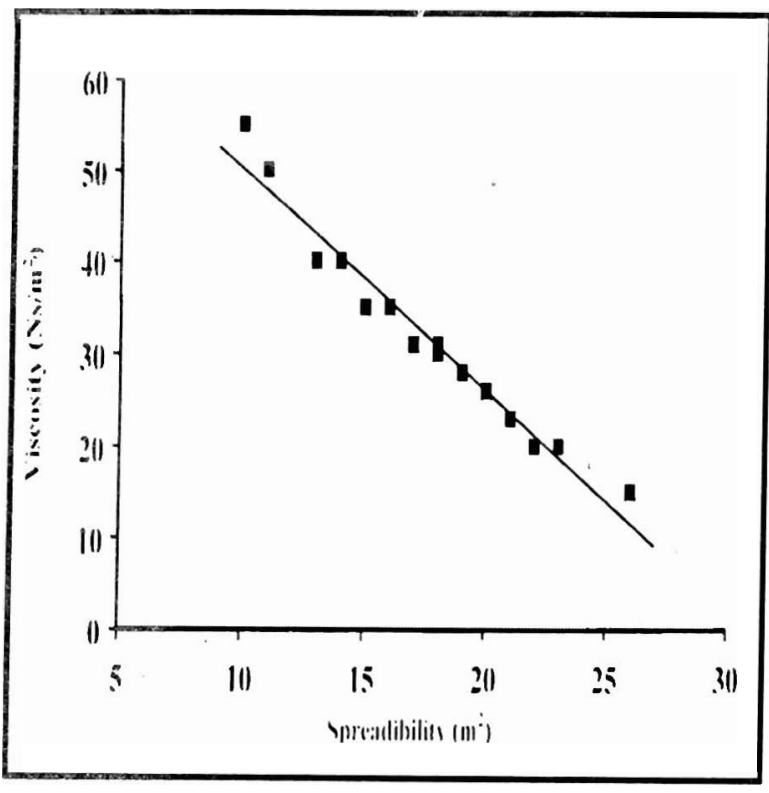

Figure 3: Relationship between the increase in viscosity and decrease in spreadibility over time of the creams stored at $40{ }^{\circ} \mathrm{C}: \mathrm{y}=-\mathbf{2 . 4 0 8 8} \mathrm{x}+\mathbf{7 4 . 1 6 8}$ $\left(R^{2}=0.96\right)$
After 8 weeks the SPF values, calculated from MPF values such as that shown in Figure 1, of the three formulations stored at 25 and $40{ }^{\circ} \mathrm{C}$ were measured and compared to initial values. The mean SPF value obtained for Furmula 1, was not significantly different from the original SPF value (Table 2). The $U V_{A} / U V_{B}$ ratio, 0.8 , also remained the same. This showed that the SPF value for Formulation 1 was not influenced by stability testing. The mean SPF values of Formulation 2 and 3 , after 8 weeks at $25^{\circ} \mathrm{C}$, were also not significantly different from that at time 0 , but for these formulation the SPF values for the samples stored at $40^{\circ} \mathrm{C}$ was significantly higher (Table 2). The increase in SPF value was most probably due to a loss of moisture from the creams at this temperature. The loss of water also lead to an increase in viscosity as discussed earlier. The $\mathrm{UV}_{\mathrm{A}} / \mathrm{UV}_{\mathrm{B}}$ ratio of Formulation 2 decreased from 0.9 to only 0.8 and that of Formulation 3 increased from 0.8 to 1.0 . The slight decrease in $\mathrm{UV}_{\mathrm{A}} / \mathrm{UV}_{\mathrm{B}}$ ratio of Formulation 2 could be due to the physical changes in this cream that led to an uneven distribution of the sun protection agents throughout the cream.

\section{DISCUSSION}

The SPF values determined after stability testing showed that the creams sun protection factors remained above the required 20 , but that storage at higher temperatures did change the $U_{A} / U V_{B}$ ratio for Formulation 3. Since the SPF value determines the effectiveness of these products Formulation 1 and 2 seems to be the best sunscreen formulations for use by, people with albinism. Based on the information obtained from the stability program, it was also clear that the $\mathrm{pH}$ and density of the three prototype creams did not change. There was a strong correlation between the viscosity and spreadibility experiments. Figure 3 show that as the viscosity increased, the spreadibility decreased. Evaluation of the physical stability showed that Formulations 1 and 2 were most stable. This conclusion was based on the observations that these formulae showed the best stability profile at all temperatures, even though, there was a slight change in structure when stored at $40{ }^{\circ} \mathrm{C}$ and $75 \%$ relative humidity, no visible separation or instability occurred and values 
obtained for densities, $\mathrm{pH}$, spreadibility, and viscosity did not change.

\section{CONCLUSION}

The results from this study showed that it is possible to formulate a sunscreen product, Formulation 1 and 2 listed in Table 1, containing a combination of inorganic oxides and organic sunscreen filters to produce a hypoallergenic sun protection product for people with albinism. However, to achieve this not only the physicochemical aspects of product formulation had to be considered, but also the very different skin type of people with albinism. Product stability, storage requirements, cost effectiveness and user compliance were also important considerations that allowed for the successful formulation of a sunscreen product for albinos.

\section{ACKNOWLEDGEMENT}

This work was supported by a grant from the National Research Foundation, Pretoria, South Africa.

\section{REFERENCES}

[1] C.J. Witkop. Clin. Derm. 7 (1989) 80-91.

[2] M.F. Naylor and K.C. Farmer. Sunscreens. Electronic textbook of dermatology. Internet Dermatology Society. Last update: April 24, 1996. http://www.telemedicine.org/sundam2.4.2 .html.

[3] A.N. Okoro. Br. J. Derm. 92 (1975) 485492.

[4] P.M. Farr and B.L Diffey. Br. J. Derm. $112(1985)$ 113-118.

[5] S.L. Sellers and F.G. Carpenter, Cosmet. Toilet. 107 (1992) 119-122.

[6] K. Narsai, M.M. De Villiers and J. Du Plessis. Pharm. 52 (1997) 486-487. 